\title{
Metabolic background determines the importance of NOS3 polymorphisms in restenosis after percutaneous coronary intervention: A study in patients with and without the metabolic syndrome
}

\author{
Douwe Pons $^{\mathrm{a}, \mathrm{b}, *}$, Pascalle S. Monraats ${ }^{\mathrm{a}, \mathrm{b}}$, Aeilko H. Zwinderman ${ }^{\mathrm{c}}$, Moniek P.M. de Maat ${ }^{\mathrm{d}}$, \\ Pieter A.F.M. Doevendans ${ }^{\mathrm{e}}$, Robbert J. de Winter ${ }^{\mathrm{f}}$, René A. Tio ${ }^{\mathrm{g}}$, Johannes Waltenberger ${ }^{\mathrm{i}}$ and \\ J. Wouter Jukema ${ }^{\mathrm{a}, \mathrm{b}, \mathrm{i}}$ \\ ${ }^{a}$ Department of Cardiology, Leiden University Medical Center, Leiden, The Netherlands \\ ${ }^{\mathrm{b}}$ Interuniversity Cardiology Institute of the Netherlands (ICIN), Utrecht, The Netherlands \\ ${ }^{\mathrm{c}}$ Department of Medical Statistics, Academic Medical Center, Amsterdam, The Netherlands \\ ${ }^{\mathrm{d}}$ Department of Hematology, Erasmus University Medical Center, Rotterdam, The Netherlands \\ ${ }^{\mathrm{e}}$ Department of Cardiology, University Medical Center Utrecht, Utrecht, The Netherlands \\ ${ }^{\mathrm{f}}$ Department of Cardiology, Academic Medical Center, Amsterdam, The Netherlands \\ ${ }^{\mathrm{g}}$ Department of Cardiology, University Medical Center Groningen, Groningen, The Netherlands \\ ${ }^{\mathrm{h}}$ Department of Cardiology, Academic Hospital Maastricht, Maastricht, The Netherlands \\ ${ }^{\mathrm{i}}$ Durrer Center for Cardiogenetic Research, Amsterdam, The Netherlands
}

\begin{abstract}
Variation in the NOS3 gene has been related to the development of restenosis. The Glu298Asp polymorphism has previously been investigated for its effect on NO levels and the development of restenosis. However, the variability of findings gave rise to the hypothesis that the functional significance of this polymorphism may only become manifest under conditions of endothelial dysfunction. Since patients with the metabolic syndrome are known to have endothelial dysfunction, we aimed to investigate if the significance of NOS3 polymorphisms may depend on the presence of the metabolic syndrome.

We examined the impact of the $-949 \mathrm{~A} / \mathrm{G}$, the $-716 \mathrm{C} / \mathrm{T}$ and the Glu298Asp polymorphisms in the NOS3 gene on the risk of clinical restenosis in a previously described subpopulation of the GENDER-study, a multicenter prospective study design that enrolled consecutive patients after successful PCI. This subpopulation consisted of 901 patients of whom sufficient data were available to establish absence or presence of the metabolic syndrome. Of these patients, 448 had the metabolic syndrome. Clinical restenosis, defined as target vessel revascularization (TVR), was the primary endpoint.

We demonstrated that the minor $-949 \mathrm{G},-716 \mathrm{~T}$ and 298Asp alleles were associated with a significantly increased risk of TVR in patients with the metabolic syndrome (HR: 1.58 [95\%CI: 1.04-2.40], HR: 1.95 [95\%CI: 1.02-3.70] and HR: 1.67 [95\%CI: 1.092.54], respectively). In the group without the metabolic syndrome we observed no association between the three polymorphisms and TVR.
\end{abstract}

\footnotetext{
${ }^{*}$ Corresponding author: D. Pons, MD, Department of Cardiology, Leiden University Medical Center, C5-P, PO Box 9600, 2300 RC,
}

Leiden. Tel: +31 62 4730665; Fax: +31 71 5266885; E-mail: d.pons @lumc.nl. 
We suggest that the metabolic alterations present in patients with the metabolic syndrome influence the functional significance of these polymorphisms and increase the susceptibility of carriers of one of these variations in the NOS3 gene to develop restenosis after PCI.

Keywords: Restenosis, percutaneous coronary intervention, metabolic syndrome, nitric oxide synthase, polymorphisms

\section{Introduction}

The frequent occurrence of restenosis is a major limitation to percutaneous coronary intervention (PCI) in patients with coronary artery disease. Patients at increased risk for restenosis could benefit from alternative treatment options such as drug-eluting stents or coronary artery bypass surgery. To be able to stratify patients with regard to their risk of developing restenosis, it is important to determine both inherited and clinical factors influencing this complex and multifactorial process.

Nitric oxide (NO) is a vasodilatory molecule known to inhibit adhesion of platelets [27] and leukocytes [16] to the vessel wall and to decrease proliferation and migration of vascular smooth muscle cells (VSMCs) [9], which are all processes known to play an important role in the development of restenosis [3]. Due to its favourable actions in these processes, NO is likely to play a protective role in the formation of restenosis. Restenosis has already been related to alterations in nitric oxide synthase (NOS) expression [24] and impaired NO-dependent endothelial vasodilation [43]. In support of these observations, Piatti et al. showed a lack of NO release after an oral glucose tolerance test (OGTT) in patients with restenosis [26]. Since endothelial NOS catalyses the formation of NO from L-arginine in endothelial cells, polymorphisms in the NOS3 gene could influence NO formation and thereby play a role in the process of restenosis. The Glu298Asp polymorphism in the NOS3 gene has previously been investigated. However, data on its influence on NO levels and the development of restenosis are still conflicting. Sofowora et al. suggested that the functional significance of this polymorphism may only become manifest under conditions of endothelial dysfunction [32]. Since endothelial dysfunction is an important characteristic of the metabolic syndrome, we hypothesize that the metabolic alterations present in patients with the metabolic syndrome may influence the functional significance of NOS3 polymorphisms. Therefore, the aim of this study was to examine whether the $-949 \mathrm{~A} / \mathrm{G}$, the $-716 \mathrm{C} / \mathrm{T}$ and the Glu298Asp polymorphisms in the NOS3 gene are related to the risk of restenosis after PCI in patients with and without the metabolic syndrome. The GENDER protocol was designed to allow separate analyses in a prespecified subgroup of patients with the metabolic syndrome.

\section{Patients and methods}

The present study population has been described previously [4]. In brief, the GENetic DEterminants of Restenosis project (GENDER) was designed to study the association between genetic polymorphisms and clinical restenosis. Patients were eligible for inclusion if they were successfully treated for stable angina, non-ST-elevation acute coronary syndromes or silent ischemia by PCI. Patients treated for acute ST elevation myocardial infarction were excluded. All patients were treated in 4 of the 13 referral centers for interventional cardiology in the Netherlands. The overall inclusion period lasted from March 1999 until June 2001. We determined the lipid profile (serum triglycerides, serum total cholesterol, serum HDL-cholesterol) and fasting serum glucose in a subpopulation of patients of whom plasma was collected. The study protocol conforms to the Declaration of Helsinki and was approved by the Medical Ethics Committees of each participating institution. Written informed consent was obtained from each participant before the PCI procedure.

\subsection{PCI procedure}

Standard angioplasty and stent placement were performed by experienced operators using a radial or femoral approach. Before the procedure, patients received aspirin $300 \mathrm{mg}$ and heparin $7500 \mathrm{IU}$. The use of intracoronary stents and additional medication, such as glycoprotein IIb/IIIa inhibitors, was at the discretion of the operator. In case of stent implantation, patients received either ticlopidin or clopidogrel for at least one month following the procedure depending on local practice. During the study, no drug-eluting stents were used. 


\subsection{Follow-up and study endpoints}

Follow-up lasted at least nine months, except when a coronary event occurred. Patients were either seen in the outpatient clinic or contacted by telephone. Restenosis was defined by target vessel revascularization (TVR), either by PCI or coronary artery bypass grafting (CABG). An independent clinical events committee adjudicated the clinical events.

Events occurring within the first month were excluded from the analysis, since these events were attributable mainly to sub-acute stent thrombosis or occluding dissections, and less likely to restenosis. Data were collected with standardized case-report forms that were completed by the research coordinator at each site. Representatives from the data-coordinating center monitored all sites.

\subsection{Genotyping}

Blood was collected in EDTA tubes at baseline and DNA was extracted following standard procedures. The NOS3 -949 A/G (rs1800779), -716 C/T (rs3918226) and the $5219 \mathrm{G} / \mathrm{T}$ (rs1799983) polymorphism, resulting in the amino acid substitution Glu298Asp, were determined by a validated multilocus genotyping assay (Roche Molecular Systems) [6]. The Glu298Asp polymorphism has already been implicated in coronary artery disease [2] and restenosis [12, 35]. The $-949 \mathrm{~A} / \mathrm{G}$ polymorphism was selected on the basis of its involvement in atherosclerotic disease [15] and the $-716 \mathrm{C} / \mathrm{T}$ polymorphism is located between the cAMP regulatory element (nt -726 to -732 ) and an activator protein-1 binding domain (nt -655 to -661) [39], which suggests a potential involvement in gene regulation.

In short, each DNA sample was amplified in a multiple polymerase chain reaction (PCR) using biotinylated primers. The PCR product pool was then hybridized to a matching panel of sequence-specific oligonucleotide probes, immobilized in a linear array on nylon membrane strips. A colorimetric detection method based on incubation with streptavidin-horseradish peroxidase conjugate, using hydrogen peroxide and 3,3',5,5'tetramethylbenzidine as substrates, was used. Operators blinded to restenosis status performed genotyping.

To confirm genotype assignments, the PCR-procedure was performed in replicate on $10 \%$ of the samples. Two independent observers carried out scoring. Disagreements $(<1 \%)$ were resolved by further joint reading, and when necessary, genotyping was repeated.

\subsection{Definitions}

Patients were defined as having metabolic syndrome by presence of three or more of the following criteria: 1) triglyceride level $\geqslant 1.7 \mathrm{mmol} / 1(150 \mathrm{mg} / \mathrm{dl})$; 2) HDL cholesterol level $<1.04 \mathrm{mmol} / 1$ (40 mg/dl) in men and $<1.3 \mathrm{mmol} / \mathrm{l}(50 \mathrm{mg} / \mathrm{dl})$ in women; 3$)$ systolic blood pressure $\geqslant 130 \mathrm{mmHg}$ and/or diastolic blood pressure $\geqslant 85 \mathrm{mmHg}$; 4) obesity, defined as BMI $>$ $28.8 \mathrm{~kg} / \mathrm{m}^{2}$, which was equivalent to a waist circumference of $102 \mathrm{~cm}$ in a cross-sectional study and similar to the BMI value $\left(28.2 \mathrm{~kg} / \mathrm{m}^{2}\right)$ calculated in a regression of BMI on waist circumference in a large population of Scottish men $[18,30]$ and 5) fasting glucose level $\geqslant$ $5.55 \mathrm{mmol} / \mathrm{l}(100 \mathrm{mg} / \mathrm{dl})$, above which patients have either pre-diabetes (impaired fasting glucose) or diabetes. This level was established by the American Diabetes Association and suggested as the new cut point for identifying the lower boundary to define an elevated glucose level as one criterion for the metabolic syndrome $[1,10,14]$.

\subsection{Statistical methodology}

Allele frequencies were determined by gene counting, the $95 \%$ confidence intervals of the allele frequencies were calculated from sample allele frequencies, based on the approximation of the binominal and normal distributions in large sample sizes. Continuous variables are expressed as mean \pm standard deviation and were compared by means of an unpaired, two-sided $t$ test. Discrete variables are expressed as counts or percentages and were compared with a chi-square test.

The association between each of the 3 polymorphisms and TVR was determined using a Cox proportional regression model. If less than 10 patients were homozygous for a particular allele, the homozygotes and heterozygotes were combined. Polymorphisms with independent prognostic value were selected in a multivariable regression model, also containing clinical and procedural risk factors.

To investigate possible additive effects of haplotypes of the NOS3 polymorphisms on TVR risk, we analyzed haplotype effects using the THESIAS program (www.genecanvas.org), which implements the stochastic-EM (Expectation-Maximization) algorithm and allows the use of Cox proportional hazards survival regression [38]. Statistical analyses were carried out using SPSS 12.0 for Windows (SPSS Inc., Chicago, IL, USA). 


\section{Results}

The characteristics of this patient sample have been described previously [4]. In summary, a total of 3,146 patients had complete follow-up $(99.3 \%)$ with a median duration of 9.6 months (interquartile range 3.9 months). Out of 3,146 patients 42 experienced an event in the first 30 days and were therefore excluded from further analysis, according to the protocol. In a previously described subpopulation of 901 patients [28], data were sufficient to establish absence or presence of metabolic syndrome. Of these patients, 448 (49.7\%) had metabolic syndrome ( $\geqslant 3$ of the 5 characteristics). The prevalence of metabolic syndrome characteristics in patients with and without the metabolic syndrome, as well as demographic, clinical and lesion characteristics, are presented in Table 1. The presence of one or more components of the metabolic syndrome was common in both sexes: $16.3 \%$ had one component, $29.6 \%$ had two components, $26.9 \%$ had three components, $15.9 \%$ had four components, and $7.0 \%$ had all five components. Except for the presence of diabetes, the prevalence of factors that were previously found to be related to restenosis did not differ between the two groups. However, patients with the metabolic syndrome had higher insulin levels and were more frequently treated with statins or insulin.

At follow-up 47 patients (10.5\%) with the metabolic syndrome versus $45(9.9 \%)$ without the metabolic syndrome underwent TVR. On multivariable Cox regression, there was no significant increase in risk of TVR in patients with the metabolic syndrome (HR: 1.03 [95\% CI: 0.68-1.57]).

Genotyping of the $-949 \mathrm{~A} / \mathrm{G}$, the $-716 \mathrm{C} / \mathrm{T}$ and the Glu298Asp (G/T) polymorphisms was successful in $96.9 \%, 96.7 \%$ and $96.9 \%$ of patients with the metabolic syndrome and in $98.7 \%, 98.2 \%$ and $98.2 \%$ of those without the metabolic syndrome, respectively. Results of the remaining patients were missing due to lack of DNA or inconclusive genotyping. In both groups, the frequencies of the minor $-949 \mathrm{G},-716 \mathrm{~T}$ and 298Asp alleles were $0.37,0.09$ and 0.31 , respective1y. The genotype distributions were consistent with Hardy-Weinberg equilibrium and did not differ significantly between patients with the metabolic syndrome and controls $(p>0.05)$.

Univariate Cox regression in patients with the metabolic syndrome revealed a significant association between the $-949 \mathrm{~A} / \mathrm{G}$, the $-716 \mathrm{C} / \mathrm{T}$ and the Glu298Asp polymorphisms and the rate of TVR (HR: 1.58 [95\%CI: 1.04-2.40] $p=0.034$, HR: 1.95 [95\%CI: 1.02-3.70] $p=0.042$ and HR: 1.67 [95\%CI: 1.09-2.54] $p=0.018$, respectively) (Table 2 ).

TVR occurred more often in -949 GG homozygotes (18.2\%) than in AG heterozygotes $(11.0 \%)$ or AA homozygotes $(7.6 \%)$. Since only one patient was homozygous for the -716T allele, we combined homozygous and heterozygous patients for this polymorphism. This combined group had an increased risk of TVR (17.6\%) when compared to the group with the -716 CC genotype (9.2\%). Homozygotes and heterozygotes for the 298Asp allele also had a higher risk of TVR ( $21.1 \%$ and $11.5 \%$, respectively) when compared to the Glu/Glu genotype (7.8\%).

In contrast, in patients without the metabolic syndrome, the $-949 \mathrm{~A} / \mathrm{G},-716 \mathrm{C} / \mathrm{T}$ and the Glu298Asp polymorphisms were not associated with TVR (HR: 0.90 [95\%CI: 0.57-1.43] $p=0.65$, HR: 0.33 [95\%CI: 0.10-1.08] $p=0.067$ and HR: 1.02 [95\%CI: $0.66-$ 1.59] $p=0.93$, respectively). For each polymorphism, TVR-risks were equal in the different genotype groups (Table 2).

After adjustment for patient and intervention-related characteristics that were previously described to be related to TVR risk, such as age, sex, hypertension, diabetes, current smoking, stenting, total occlusion and residual stenosis $>20 \%$, the $-949 \mathrm{~A} / \mathrm{G}$, the $-716 \mathrm{C} / \mathrm{T}$ and the Glu298Asp polymorphisms were predictors of TVR (HR: 1.55 [95\%CI: 1.01-2.37] $p=0.043$, HR: 2.05 [95\%CI: 1.05-4,00] $p=0.034$ and HR: 1.68 [95\%CI: 1.09-2.59] $p=0.019$, respectively).

As determined with haploview, the $-949 \mathrm{~A} / \mathrm{G}$ and $-716 \mathrm{C} / \mathrm{T}$ polymorphisms revealed significant linkage disequilibrium (D': 0.95) and were combined into haplotypes for further analysis. The Glu298Asp polymorphism was excluded from this analysis due to the lack of linkage disequilibrium between this polymorphism and the $-949 \mathrm{~A} / \mathrm{G}$ polymorphism (D': 0.45). In both groups, frequencies of the $-949 \mathrm{~A} /-716 \mathrm{C}$, 949G/-716C and -949G/-716T haplotypes were 0.62, 0.29 and 0.08 , respectively. Due to its low frequency $(0.007$ in patients with the metabolic syndrome and 0.008 in patients without the metabolic syndrome), the -949A/-716T haplotype was excluded from the analysis. A haplotype-based risk analysis in patients with the metabolic syndrome revealed a significant association of the $-949 \mathrm{G} /-716 \mathrm{~T}$ haplotype with the risk for TVR when compared to -949A/-716C, the most frequent reference haplotype (HR: 2.89 [95\%CI: 1.45-5.76], $p=$ 0.0026 (Fig. 1)). 
Table 1

Baseline and metabolic syndrome characteristics by metabolic syndrome status $(N=901)$

\begin{tabular}{lllr}
\hline & \multicolumn{2}{c}{ Metabolic syndrome } & \\
\cline { 2 - 3 } & Absent & Present & $P$ value \\
\hline Baseline Characteristics: & $N=453$ & $N=448$ & \\
Age $(\mathrm{y} \pm \mathrm{SD})$ & $63( \pm 10)$ & $61( \pm 11)$ & 0.003 \\
BMI $\left(\mathrm{kg} / \mathrm{m}^{2} \pm \mathrm{SD}\right)$ & $25.4( \pm 3.0)$ & $28.7( \pm 4.1)$ & $<0.001$ \\
Female sex $(\%)$ & $127(28)$ & $131(29)$ & 0.69 \\
Diabetes Mellitus $(\%)$ & $32(7)$ & $108(24)$ & $<0.001$ \\
Current smoking $(\%)$ & $80(18)$ & $94(21)$ & 0.21 \\
Stent placement $(\%)$ & $376(80)$ & $373(83)$ & 0.92 \\
Residual stenosis $(\%)$ & $51(11)$ & $44(10)$ & 0.52 \\
Total occlusion $(\%)$ & $32(7)$ & $41(9)$ & 0.27 \\
Total cholesterol $(\mathrm{mmol} / \mathrm{L}, \pm \mathrm{SD})$ & $4.91( \pm 1.05)$ & $5.01( \pm 1.12)$ & 0.32 \\
Statins $(\%)$ & $231(51)$ & $265(59)$ & 0.014 \\
Insulin $\left.{ }^{\mathrm{b}}(\mathrm{m}) / \mathrm{l}, \mathrm{IQR}\right)$ & $12(9)$ & $20(20)$ & $<0.001$ \\
Insulin therapy $(\%)$ & $13(3)$ & $32(7)$ & 0.003 \\
Metabolic Syndrome Characteristics & & & \\
BMI $>28.8 \mathrm{~kg} / \mathrm{m}^{2}$ & $37(8.2 \%)$ & $207(46.2 \%)$ & \\
Triglycerides $\geqslant 1.7$ mmol/L & $128(28.3 \%)$ & $370(82.6 \%)$ & \\
HDL cholesterol $<1.04$ mmol/L men and & $128(28.3 \%)$ & $324(72.3 \%)$ & \\
$<1.3$ mmol/L women & & & \\
Systolic BP $\geqslant 130$ and diastolic BP & $273(60.3 \%)$ & $383(85.5 \%)$ & \\
$\geqslant$ 85 mm Hg & & & \\
Fasting glucose $\geqslant 5.55$ mmol/L & $115(25.4 \%)$ & $329(73.4 \%)$ & \\
\hline
\end{tabular}

${ }^{a}$ p-value of the nonparametric Mann-Whitney test, or chi-square test.

b Insulin levels are presented as median with interquartile range (IQR).

Table 2

Cox regression of NOS3 polymorphisms in association with TVR in patients with and without the metabolic syndrome

\begin{tabular}{|c|c|c|c|c|}
\hline Metabolic syndrome & Polymorphisms & Number of patients & TVR $(\%)$ & HR $(95 \% \mathrm{CI})$ \\
\hline \multirow[t]{12}{*}{ Present $(N=448)$} & $-949 \mathrm{~A} / \mathrm{G}$ & & & \\
\hline & AA & 170 & 7.6 & $1.58(1.04-2.40)$ \\
\hline & $\mathrm{AG}$ & 209 & 11.0 & \\
\hline & GG & 55 & 18.2 & \\
\hline & $-716 \mathrm{C} / \mathrm{T}$ & & & \\
\hline & $\mathrm{CC}$ & 359 & 9.2 & $1.95(1.02-3.70)$ \\
\hline & CT & 73 & 17.6 & \\
\hline & TT & 1 & & \\
\hline & Glu298Asp (G/T) & & & \\
\hline & GG & 204 & 7.8 & $1.67(1.09-2.54)$ \\
\hline & GT & 192 & 11.5 & \\
\hline & TT & 38 & 21.1 & \\
\hline \multirow[t]{12}{*}{ Absent $(N=453)$} & $-949 \mathrm{~A} / \mathrm{G}$ & & & \\
\hline & $\mathrm{AA}$ & 167 & 10.8 & $0.90(0.57-1.43)$ \\
\hline & AG & 226 & 8.4 & \\
\hline & GG & 54 & 11.1 & \\
\hline & $-716 \mathrm{C} / \mathrm{T}$ & & & \\
\hline & $\mathrm{CC}$ & 374 & 10.7 & $0.33(0.10-1.08)$ \\
\hline & $\mathrm{CT}$ & 63 & 4.2 & \\
\hline & TT & 8 & & \\
\hline & Glu298Asp (G/T) & & & \\
\hline & GG & 219 & 10.0 & $1.02(0.66-1.59)$ \\
\hline & GT & 174 & 8.0 & \\
\hline & TT & 52 & 13.5 & \\
\hline
\end{tabular}

\section{Discussion}

To test our hypothesis that the functional significance of NOS3 polymorphisms may depend on the presence of the metabolic syndrome, we studied the relationship between these polymorphisms and the risk of restenosis in a subpopulation of patients with the metabolic syndrome that took part in a large follow-up study of 


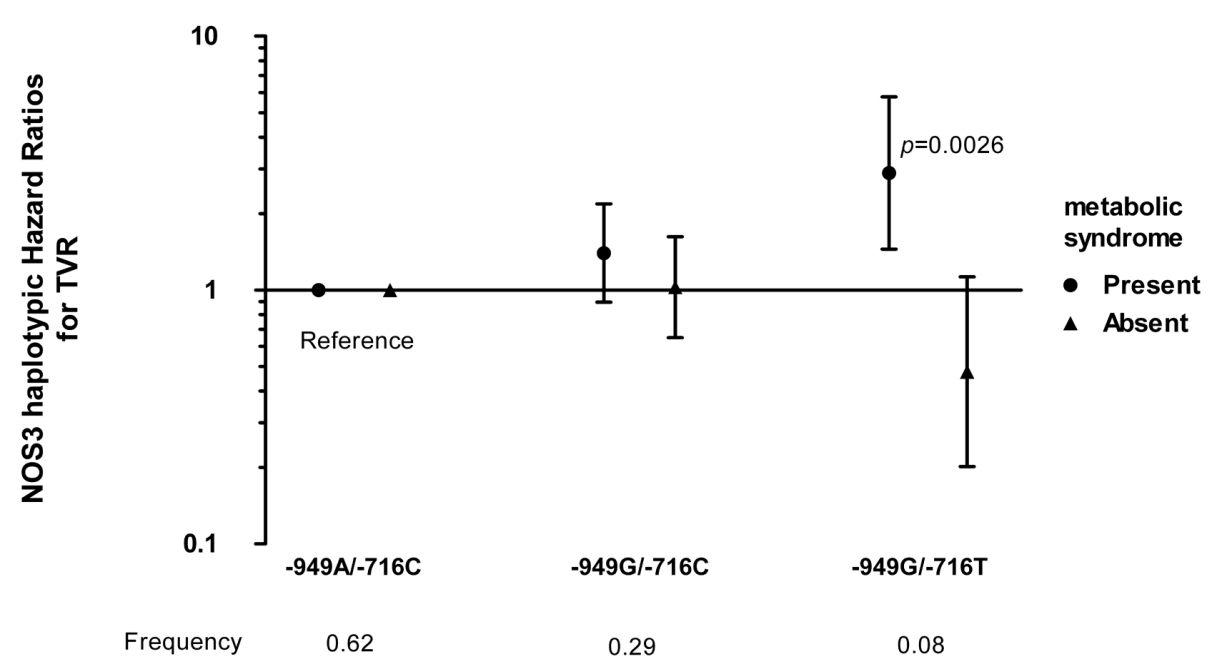

Fig. 1. NOS3 haplotype effects on the risk for target vessel revascularization (TVR) in patients with (circles) and without (triangles) the metabolic syndrome. Hazard ratios by reference to the most frequent haplotype were calculated using the THESIAS software. The -949G/-716T promoter haplotype showed a strong association with TVR (HR: 2.89 [95\% CI: 1.45-5.76], $p=0.0026$ ), which indicates that both polymorphisms contribute separately to the risk of TVR.

unselected, consecutive patients undergoing PCI. We demonstrated that the $-949 \mathrm{G},-716 \mathrm{~T}$ and $298 \mathrm{Asp}$ variants in the NOS3 gene were associated with a highly increased risk of TVR after PCI in patients with the metabolic syndrome, but not in patients without the metabolic syndrome.

Of the $-949 \mathrm{~A} / \mathrm{G},-716 \mathrm{C} / \mathrm{T}$ and Glu298Asp polymorphisms, only the Glu298Asp polymorphism has previously been investigated for its involvement in restenosis. Suzuki et al. have demonstrated that carriers of the 298Asp allele were at increased risk of developing angiographic restenosis after stent placement (OR: 3.9 [95\% CI: 1.09-13.95], after multivariate analysis) [35]. However, their population was very small $(n=85)$ and consisted of relatively many patients with diabetes $(27 \%)$. In support of their results, Gomma et al. demonstrated in a still relatively small and selected group of 205 stented patients, that possession of one or more alleles of the 298Asp variant was associated with an increased rate of angiographic restenosis after adjusting for clinical factors (OR: 2.47 [95\% CI: 1.225.00]) [12]. However, Gorchakowa et al. could not confirm these findings and demonstrated in a similar study, with a much larger patient number $(n=1850)$, that rates of angiographic restenosis or TVR did not differ significantly between the Glu298Asp genotypes [13].

The mechanism by which this polymorphism would promote neointima formation remains subject to discussion. It was originally suggested that NO would protect against restenosis because of its inhibitory role in VSMC proliferation, adhesion of leukocytes to the vessel wall and coagulation [9,16,27], processes known to be involved in restenosis [3]. In addition, NO has been shown to suppress the production of the potent vasoconstrictors endothelin and angiotensin II, that also induce VSMC proliferation [5,36]. Its role in restenosis was further established by the observation that Larginine, the precursor to NO, decreases restenotic lesion formation in the rat [41], whereas L-NAME $\left(\mathrm{N}^{{ }}\right.$nitro-L-arginine methyl ester), a non-selective NOSinhibitor, stimulates neo-intimal hyperplasia in the rabbit after balloon angioplasty [17]. In humans, intramural administration of L-arginine has been shown to reduce neointimal hyperplasia at 6 months after stent placement [34]. Furthermore, patients with in-stent restenosis had impaired endothelial vasodilation and a lack of NO-release after an OGTT when compared to patients without restenosis [26].

Although several in vitro [7] and in vivo [32,40] studies showed reduced levels of NO in Glu298Asp homozygotes, data on the functional significance of this polymorphism are still conflicting. The 298Asp variant has been shown to result in protein with twofold less activity [42] and an increased susceptibility to proteolytic cleavage [37]. However, Sessa et al. demonstrated that the observed fragmentation was an artifact of sample preparation for gel electrophoresis [8] and several authors reported similar activity of NOS3 in the different Glu298Asp genotypes [11,22]. Studies examining vasodilation in response to intrabrachial injection of acetylcholine produced conflicting results [29,31]. Furthermore, flow-mediated dilation of the brachial artery 
was not affected by the Glu298Asp polymorphism [20, 23], whereas Naber et al. demonstrated a higher coronary vascular resistance in 298Asp homozygotes compared to that of 298Glu homozygotes at rest [25]. These discrepancies might reflect the impact of interactions with environmental factors, such as smoking [2].

To explain this variability, Sofowora et al. put forward an interesting hypothesis. In spite of the observed reduction in urinary excretion of NO in 298Asp homozygotes, they could not demonstrate differences between 298Asp homozygotes and 298Glu homozygotes as to vascular responses to acetylcholine, glyceryl trinitrate or phenylephrine in a healthy population [32]. Since, in contrast to their results, 298Asp homozygous patients with ischemic heart disease were found to be more sensitive to the vasoconstrictive effects of phenylephrine, they suggested that the functional significance of the Glu298Asp polymorphism may only become manifest under conditions of endothelial dysfunction. In support of this possibility, Leeson et al. demonstrated that 298Asp homozygotes had significantly lower flow-mediated dilation than 298Glu homozygotes, only in smokers, a group known to have endothelial dysfunction [20]. Recently, smoking carriers of the 298Asp allele were also found to have an increased risk of coronary heart disease relative to nonsmokers carrying two 298Glu alleles [19].

Endothelial dysfunction is an important characteristic of the metabolic syndrome. A study by Lteif et al. showed that insulin resistance and systolic blood pressure seem to be the most important determinants of endothelial dysfunction in patients with the metabolic syndrome [21]. Furthermore, high glucose levels are also known to determine endothelial dysfunction. A recent study showed that glucose downregulates NOS3 mRNA and protein expression through regulation of mitochondrial production of reactive oxygen species (ROS) with subsequent activation of AP-1 [33]. The inhibitory effect of glucose on NOS3 gene transcription was reversed by mutation of the AP- 1 binding site in the promoter region. These findings indicate a mechanism by which hyperglycemia could increase the significance of NOS3 promoter polymorphisms.

Thus, if we assume that the functional significance of NOS3 polymorphisms depends on the presence of endothelial dysfunction, an explanation of our results may be that patients with the metabolic syndrome which carry the $-949 \mathrm{G},-716 \mathrm{~T}$ or $298 \mathrm{Asp}$ alleles produce less NO than patients without the metabolic syndrome or carriers of the $-949 \mathrm{C},-716 \mathrm{C}$ or $298 \mathrm{Glu}$ alleles. Since the $-949 \mathrm{G} /-716 \mathrm{~T}$ haplotype showed a stronger associa- tion with TVR than both polymorphisms individually, these alleles could even interact to reduce NOS3 activity in patients with the metabolic syndrome. Further research has to be performed to test these hypotheses.

Although the variant alleles of the three NOS3 polymorphisms did not increase the risk of restenosis in patients without the metabolic syndrome, the absolute rates of restenosis did not differ between subgroups with and without the metabolic syndrome. This implies that some other yet unknown factors may have contributed separately to the rate of restenosis in the group without the metabolic syndrome.

\subsection{Limitations of the study}

One of the limitations of our study is that we did not have waist circumference as per criteria of ATPIII. We therefore substituted waist circumference with variable of obesity as defined by BMI of $>28.8 \mathrm{~kg} / \mathrm{m}^{2}$, this cutoff was equivalent to a waist circumference of $102 \mathrm{~cm}$ in a cross-sectional study and similar to the BMI value $\left(28.2 \mathrm{~kg} / \mathrm{m}^{2}\right)$ calculated in a regression of BMI on waist circumference in a large population of Scottish men [18,30].

In our study we lack data on NOS3 activity or NO concentration. Abundant data is present on the functionality of the Glu298Asp polymorphism. However, little is known about a difference of NOS3 activity between patients with and without the metabolic syndrome. We would like to promote research that compares NOS3 activity and local NO concentrations between patients with the metabolic syndrome and controls having specific genotypes of the $-949 \mathrm{~A} / \mathrm{G},-716$ $\mathrm{C} / \mathrm{T}$ and Glu298Asp polymorphisms.

\section{Conclusions}

In conclusion, we have demonstrated that the variant alleles of the $-949 \mathrm{~A} / \mathrm{G},-716 \mathrm{C} / \mathrm{T}$ and Glu298Asp polymorphisms increase the risk of TVR in patients with the metabolic syndrome, but not in patients without the metabolic syndrome. We suggest that the metabolic alterations in these patients influence the functional significance of the three NOS3 polymorphisms and increase the susceptibility of carriers of these variations in the NOS3 gene to develop restenosis after PCI. Genotyping for these polymorphisms may lead to better risk stratification and more tailored therapy in patients with the metabolic syndrome to prevent TVR after PCI. 


\section{Acknowledgements}

This study was supported by grant 99.210 from the Netherlands Heart Foundation and a grant from the Interuniversity Cardiology Institute of the Netherlands (ICIN). Dr JW Jukema is an Established Clinical Investigator of the Netherlands Heart Foundation (2001 D 032).

\section{References}

[1] Executive Summary of The Third Report of The National Cholesterol Education Program (NCEP) Expert Panel on Detection, Evaluation, and Treatment of High Blood Cholesterol In Adults (Adult Treatment Panel III), JAMA 285 (2001), 2486-2497.

[2] W.R. Agema, M.P. De Maat, A.H. Zwinderman, J.J. Kastelein, T.J. Rabelink, A.J. van Boven, E.J. Feskens, J.M. Boer, E.E. van der Wall and J.W. Jukema, An integrated evaluation of endothelial constitutive nitric oxide synthase polymorphisms and coronary artery disease in men, Clin Sci (Lond) 107 (2004), 255-261.

[3] W.R. Agema, J.W. Jukema, S.N. Pimstone and J.J. Kastelein, Genetic aspects of restenosis after percutaneous coronary interventions: towards more tailored therapy, Eur Heart $J \mathbf{2 2}$ (2001), 2058-2074.

[4] W.R.P. Agema, P.S. Monraats, A.H. Zwinderman, R.J. de Winter, R.A. Tio, P.A.F.M. Doevendans, J. Waltenberger, M.P.M. de Maat, R.R. Frants, D.E. Atsma, A. van der Laarse, E.E. van der Wall and J.W. Jukema, Current PTCA practice and clinical outcomes in The Netherlands: the real world in the pre-drug-eluting stent era, Eur Heart J 25 (2004), 1163-1170.

[5] C. Boulanger and T.F. Luscher, Release of endothelin from the porcine aorta. Inhibition by endothelium-derived nitric oxide, J Clin Invest 85 (1990), 587-590.

[6] S. Cheng, M.A. Grow, C. Pallaud, W. Klitz, H.A. Erlich, S. Visvikis, J.J. Chen, C.R. Pullinger, M.J. Malloy, G. Siest and J.P. Kane, A multilocus genotyping assay for candidate markers of cardiovascular disease risk, Genome Res 9 (1999), 936-949.

[7] P. Desantis, M.O. Babaoglu, J.C. Pezzullo, D.R. Abernethy and J.E.Freedman, Impaired production of platelet-derived nitric oxide in human subjects with a polymorphic variant of endothelial nitric oxide synthase, Circulation 102 (2000), S61.

[8] T.A. Fairchild, D. Fulton, J.T. Fontana, J.P. Gratton, T.J. McCabe and W.C. Sessa, Acidic hydrolysis as a mechanism for the cleavage of the Glu(298)->Asp variant of human endothelial nitric-oxide synthase, J Biol Chem 276 (2001), 2667426679.

[9] U.C. Garg and A. Hassid, Nitric oxide-generating vasodilators and 8-bromo-cyclic guanosine monophosphate inhibit mitogenesis and proliferation of cultured rat vascular smooth muscle cells, J Clin Invest 83 (1989), 1774-1777.

[10] S. Genuth, K.G. Alberti, P. Bennett, J. Buse, R. Defronzo, R. Kahn, J. Kitzmiller, W.C. Knowler, H. Lebovitz, A. Lernmark, D. Nathan, J. Palmer, R. Rizza, C. Saudek, J. Shaw, M. Steffes, M. Stern, J. Tuomilehto and P. Zimmet, Follow-up report on the diagnosis of diabetes mellitus, Diabetes Care 26 (2003), 3160-3167.
[11] R. Golser, A.C. Gorren, B. Mayer and K. Schmidt, Functional characterization of Glu298Asp mutant human endothelial nitric oxide synthase purified from a yeast expression system, Nitric Oxide 8 (2003), 7-14.

[12] A.H. Gomma, M.A. Elrayess, C.J. Knight, E. Hawe, K.M. Fox and S.E. Humphries, The endothelial nitric oxide synthase (Glu298Asp and -786T $>$ C) gene polymorphisms are associated with coronary in-stent restenosis, Eur Heart J 23 (2002), 1955-1962.

[13] O. Gorchakova, W. Koch, N. von Beckerath, J. Mehilli, A. Schomig and A. Kastrati, Association of a genetic variant of endothelial nitric oxide synthase with the 1 year clinical outcome after coronary stent placement, Eur Heart J 24 (2003), $820-827$.

[14] S.M. Grundy, H.B. Brewer, Jr., J.I. Cleeman, S.C. Smith, Jr. and C. Lenfant, Definition of metabolic syndrome: Report of the National Heart, Lung, and Blood Institute/American Heart Association conference on scientific issues related to definition, Circulation 109 (2004), 433-438.

[15] T.D. Howard, W.H. Giles, J. Xu, M.A. Wozniak, A.M. Malarcher, L.A. Lange, R.F. Macko, M.J. Basehore, D.A. Meyers, J.W. Cole and S.J. Kittner, Promoter polymorphisms in the nitric oxide synthase 3 gene are associated with ischemic stroke susceptibility in young black women, Stroke 36 (2005), 1848-1851.

[16] P. Kubes, M. Suzuki and D.N. Granger, Nitric oxide: an endogenous modulator of leukocyte adhesion, Proc Natl Acad Sci U S A 88 (1991), 4651-4655.

[17] T. Le Tourneau, E. Van Belle, D. Corseaux, B. Vallet, G. Lebuffe, B. Dupuis, J.M. Lablanche, E. McFadden, C. Bauters and M.E. Bertrand, Role of nitric oxide in restenosis after experimental balloon angioplasty in the hypercholesterolemic rabbit: effects on neointimal hyperplasia and vascular remodeling, J Am Coll Cardiol 33 (1999), 876-882.

[18] M.E. Lean, T.S. Han and C.E. Morrison, Waist circumference as a measure for indicating need for weight management, $B M J$ 311 (1995), 158-161.

[19] C.R. Lee, K.E. North, M.S. Bray, C.L. Avery, M.J. Mosher, D.J. Couper, J. Coresh, A.R. Folsom, E. Boerwinkle, G. Heiss and D.C. Zeldin, NOS3 polymorphisms, cigarette smoking, and cardiovascular disease risk: the Atherosclerosis Risk in Communities study, Pharmacogenet Genomics 16 (2006), 891-899.

[20] C.P. Leeson, A.D. Hingorani, M.J. Mullen, N. Jeerooburkhan, M. Kattenhorn, T.J. Cole, D.P. Muller, A. Lucas, S.E. Humphries and J.E. Deanfield, Glu298Asp endothelial nitric oxide synthase gene polymorphism interacts with environmental and dietary factors to influence endothelial function, Circ Res 90 (2002), 1153-1158.

[21] A.A. Lteif, K. Han and K.J. Mather, Obesity, insulin resistance, and the metabolic syndrome: determinants of endothelial dysfunction in whites and blacks, Circulation 112 (2005), 32-38.

[22] D.M. McDonald, N.J. Alp and K.M. Channon, Functional comparison of the endothelial nitric oxide synthase Glu298Asp polymorphic variants in human endothelial cells, Pharmacogenetics 14 (2004), 831-839.

[23] D.M. McNamara, R. Holubkov, J.J. Wang, A. Palmer, N.B. Merz and B.L. Sharaf, The eNOS Asp298 variant is not associated with atherosclerosis or endothelial dysfunction. Results from the NHLBI WISE study, Circulation 100 (1999), S718.

[24] P.R. Myers, R. Webel, V. Thondapu, X.P. Xu, J. Amann, M.A. Tanner, J.S. Jenkins, J.S. Pollock and M.H. Laughlin, Resteno- 
sis is associated with decreased coronary artery nitric oxide synthase, Int J Cardiol 55 (1996), 183-191.

[25] C.K. Naber, D. Baumgart, C. Altmann, W. Siffert, R. Erbel and G. Heusch, eNOS 894T allele and coronary blood flow at rest and during adenosine-induced hyperemia, Am J Physiol Heart Circ Physiol 281 (2001), H1908-H1912.

[26] P. Piatti, C. Di Mario, L.D. Monti, G. Fragasso, F. Sgura, A. Caumo, E. Setola, P. Lucotti, E. Galluccio, C. Ronchi, A Origgi, I. Zavaroni, A. Margonato and A. Colombo, Association of insulin resistance, hyperleptinemia, and impaired nitric oxide release with in-stent restenosis in patients undergoing coronary stenting, Circulation 108 (2003), 2074-2081.

[27] M.W. Radomski, R.M. Palmer and S. Moncada, Endogenous nitric oxide inhibits human platelet adhesion to vascular endothelium, Lancet 2 (1987), 1057-1058.

[28] J.S. Rana, P.S. Monraats, A.H. Zwinderman, M.P. De Maat, J.J. Kastelein, P.A. Doevendans, R.J. de Winter, R.A. Tio, R.R. Frants, L.A. van der, E.E. van der Wall and J.W. Jukema, Metabolic syndrome and risk of restenosis in patients undergoing percutaneous coronary intervention, Diabetes Care $\mathbf{2 8}$ (2005), 873-877.

[29] L.J. Rosenberg, P. Desantis, M.O. Babaoglu and D.R. Abernethy, Polymorphic variant endothelial nitric oxide synthase impairs endothelium-dependent vascular relaxation in both heterozygotes and homozygotes, Clin Pharmacol Ther 69 (2001), 89

[30] N. Sattar, A. Gaw, O. Scherbakova, I. Ford, D.S. O'Reilly, S.M. Haffner, C. Isles, P.W. Macfarlane, C.J. Packard, S.M. Cobbe and J. Shepherd, Metabolic syndrome with and without $\mathrm{C}$-reactive protein as a predictor of coronary heart disease and diabetes in the West of Scotland Coronary Prevention Study, Circulation 108 (2003), 414-419.

[31] M.P. Schneider, J. Erdmann, C. Delles, E. Fleck, V. RegitzZagrosek and R.E. Schmieder, Functional gene testing of the Glu298Asp polymorphism of the endothelial NO synthase, $J$ Hypertens 18 (2000), 1767-1773.

[32] G. Sofowora, V. Dishy, H.G. Xie, H. Imamura, Y. Nishimi, C.R. Morales, J.D. Morrow, R.B. Kim, C.M. Stein and A.J. Wood, In-vivo effects of Glu298Asp endothelial nitric oxide synthase polymorphism, Pharmacogenetics 11 (2001), 809814.

[33] S. Srinivasan, M.E. Hatley, D.T. Bolick, L.A. Palmer, D. Edelstein, M. Brownlee and C.C. Hedrick, Hyperglycaemiainduced superoxide production decreases eNOS expression via AP-1 activation in aortic endothelial cells, Diabetologia 47 (2004), 1727-1734

[34] T. Suzuki, M. Hayase, K. Hibi, H. Hosokawa, K. Yokoya, P.J.
Fitzgerald, P.G. Yock, J.P. Cooke, T. Suzuki and A.C. Yeung, Effect of local delivery of L-arginine on in-stent restenosis in humans, Am J Cardiol 89 (2002), 363-367.

[35] T. Suzuki, K. Okumura, T. Sone, T. Kosokabe, H. Tsuboi, J. Kondo, H. Mukawa, H. Kamiya, T. Tomida, H. Imai, H. Matsui and T. Hayakawa, The Glu298Asp polymorphism in endothelial nitric oxide synthase gene is associated with coronary in-stent restenosis, Int J Cardiol 86 (2002), 71-76.

[36] M. Takemoto, K. Egashira, M. Usui, K. Numaguchi, H. Tomita, H. Tsutsui, H. Shimokawa, K. Sueishi and A. Takeshita, Important role of tissue angiotensin-converting enzyme activity in the pathogenesis of coronary vascular and myocardial structural changes induced by long-term blockade of nitric oxide synthesis in rats, J Clin Invest 99 (1997), 278-287.

[37] M. Tesauro, W.C. Thompson, P. Rogliani, L. Qi, P.P. Chaudhary and J. Moss, Intracellular processing of endothelial nitric oxide synthase isoforms associated with differences in severity of cardiopulmonary diseases: cleavage of proteins with aspartate vs. glutamate at position 298, Proc Natl Acad Sci USA 97 (2000), 2832-2835.

[38] D.A. Tregouet and L. Tiret, Cox proportional hazards survival regression in haplotype-based association analysis using the Stochastic-EM algorithm, Eur J Hum Genet 12 (2004), 971974.

[39] T.J. Tunny, K.A. Richardson and C.V. Clark, Association study of the 5' flanking regions of endothelial-nitric oxide synthase and endothelin-1 genes in familial primary open-angle glaucoma, Clin Exp Pharmacol Physiol 25 (1998), 26-29.

[40] B.A. Veldman, W. Spiering, P.A. Doevendans, G. Vervoort, A.A. Kroon, P.W. de Leeuw and P. Smits, The Glu298Asp polymorphism of the NOS3 gene as a determinant of the baseline production of nitric oxide, J Hypertens 20 (2002), 2023 2027.

[41] P. Vermeersch, Z. Nong, E. Stabile, O. Varenne, H. Gillijns, M. Pellens, N. Van Pelt, M. Hoylaerts, S. De, I, D. Collen and S. Janssens, L-arginine administration reduces neointima formation after stent injury in rats by a nitric oxide-mediated mechanism, Arterioscler Thromb Vasc Biol 21 (2001), 16041609.

[42] X.L. Wang, A.S. Sim, M.X. Wang, G.A. Murrell, B. Trudinger and J. Wang, Genotype dependent and cigarette specific effects on endothelial nitric oxide synthase gene expression and enzyme activity, FEBS Lett 471 (2000), 45-50.

[43] T.C. Wu, Y.H. Chen, J.W. Chen, L.C. Chen, S.J. Lin, P.Y. Ding, S.P. Wang and M.S. Chang, Impaired forearm reactive hyperemia is related to late restenosis after coronary stenting, Am J Cardiol 85 (2000), 1071-1076. 


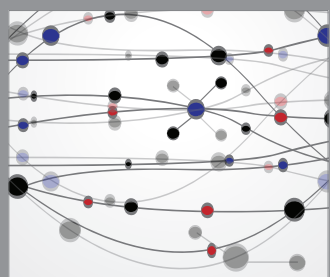

The Scientific World Journal
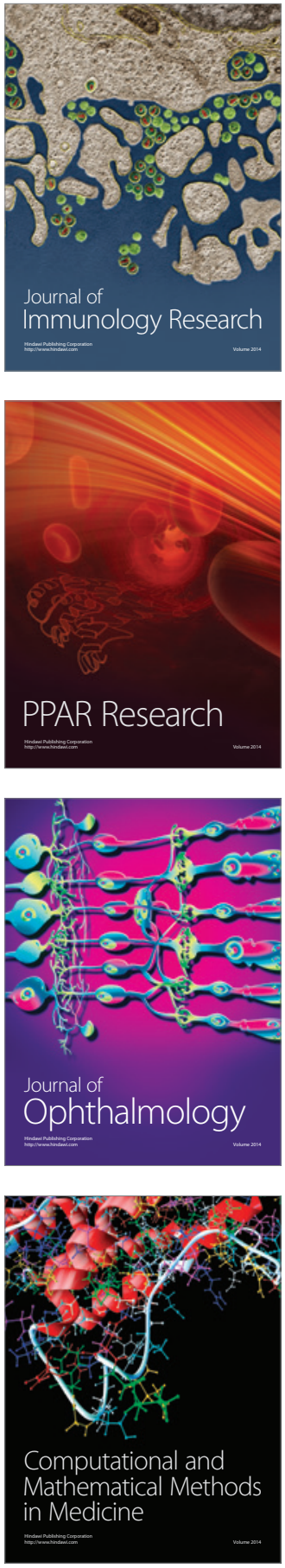

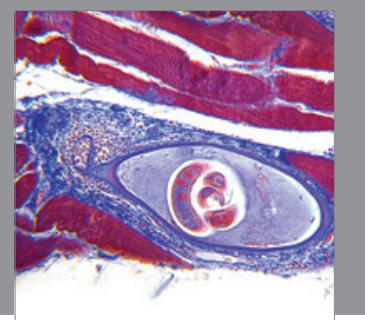

Gastroenterology

Research and Practice
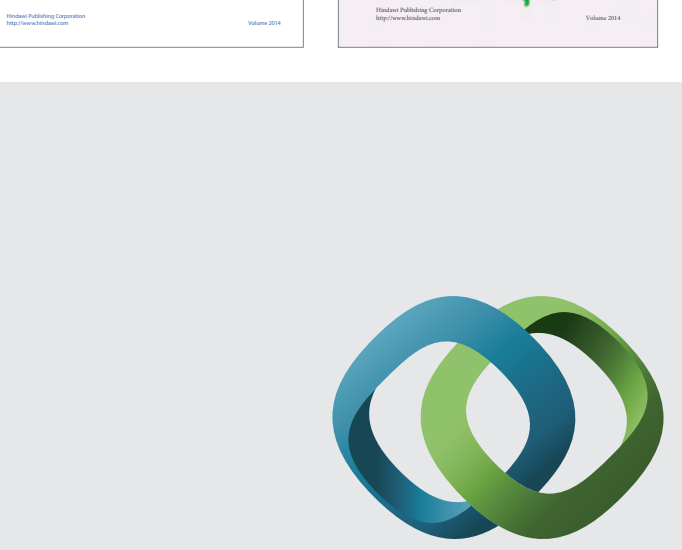

\section{Hindawi}

Submit your manuscripts at

http://www.hindawi.com
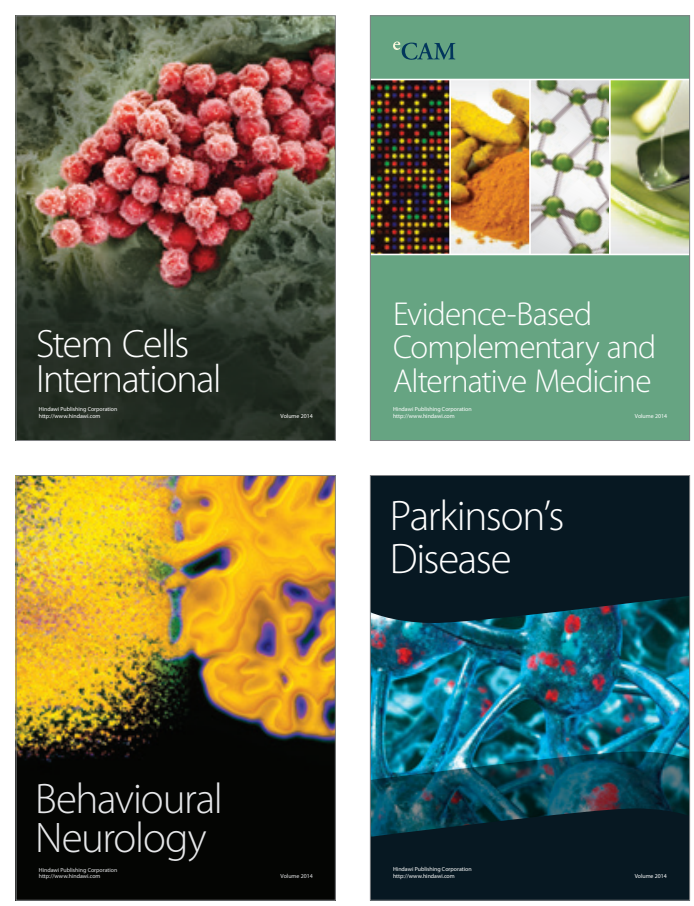

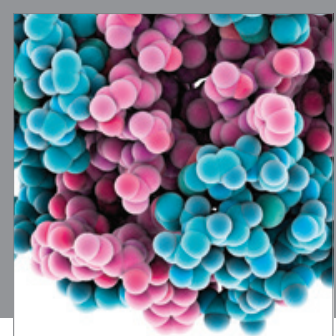

Journal of
Diabetes Research

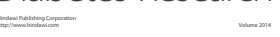

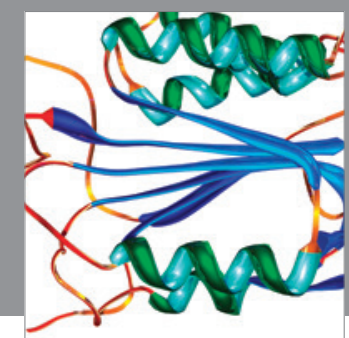

Disease Markers
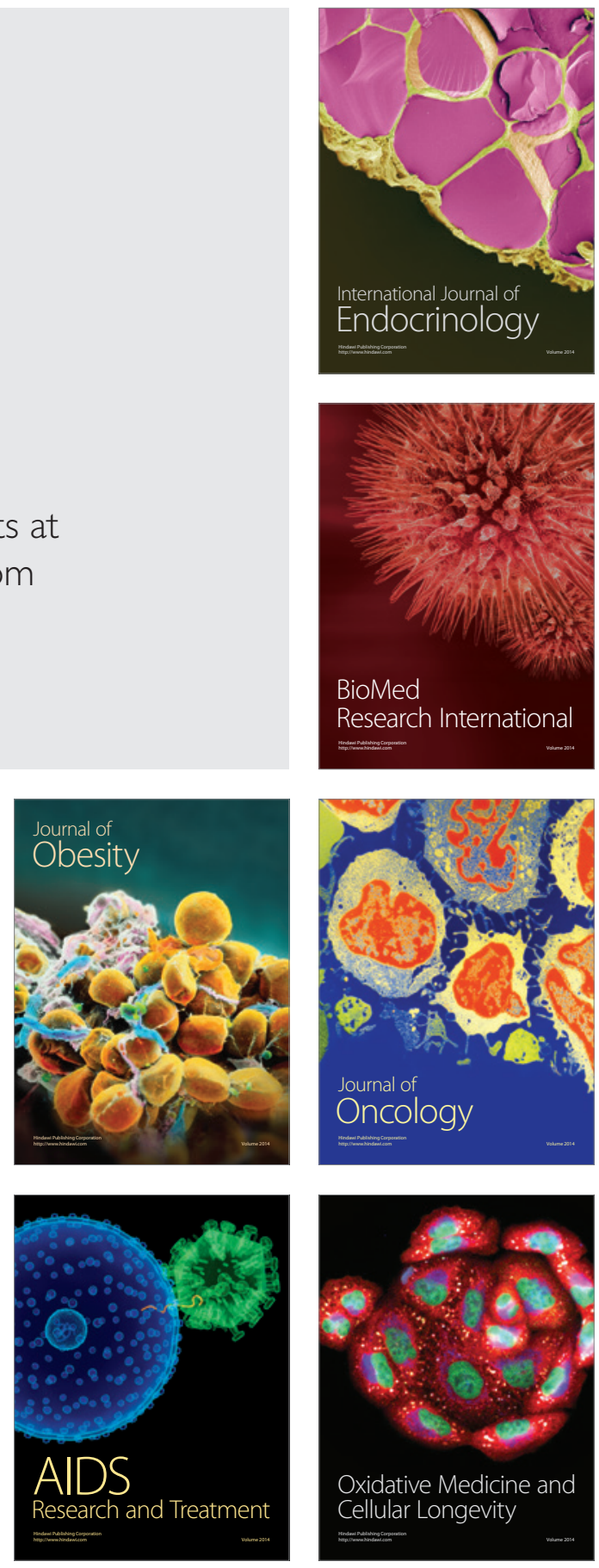